\title{
RESPONSABILIDADE CIVIL DO ESTADO POR DANO MORAL EM CASO DE MÁ UTILIZAÇÃO DE DADOS PESSOAIS
}

\author{
REGINA LINDEN RUARO*
}

\begin{abstract}
RESUMO: Com a submissão do Estado à lei constitucional surge a possibilidade de responsabilização de tal ente por danos - inclusive morais - causados a particulares. A má utilização de dados pessoais, por configurar infringência ao direito fundamental à privacidade, pode gerar o dever do Estado indenizar, desde que comprovado o dano e o nexo causal. PALAVRAS-CHAVE: Responsabilidade por Danos, Dados Pessoais, Privacidade.
\end{abstract}

ABSTRACT: The submission of the state to the Constitutional Law upholds its responsibility for damages caused to citizens, including moral damages. The misuse of personal data, violating the fundamental right to privacy, could give rise to the duty to compensate towards the State, once the damage, the injury and the causal nexus has been demonstrated. KEYWORDS: Responsibility for Damages, Personal Data, Privacy.

SUMÁRIO: 1. Introdução; 2. A Responsabilidade Civil do Estado: Uma Abordagem da Evolução; 2.1. Uma Abordagem Genérica acerca da Definição do Dano Moral; 3. Dos Direitos da Personalidade (Objeto do Dano Moral); 4. Da Responsabilidade Estatal pelo Dano Moral; 5. O Direito à Intimidade como núcleo do Direito Fundamental à Privacidade, e a Proteção de Danos; 6. Conclusões.

\section{INTRODUÇÃO}

Modernamente muito se tem discutido acerca da responsabilidade civil do Estado, sobretudo quando a matéria entra na esfera do dano moral. Tal realidade leva-nos a necessidade de estudar mais detalhadamente a responsabilização do Estado pela (má) utilização de dados pessoais. A problemática toma forma sobretudo quando tratamos tais dados como direitos fundamentais, atinentes à esfera íntima do indivíduo.

Para delimitar o estudo, ao longo da abordagem trataremos das seguintes questões: a) Como funciona a responsabilização civil do Estado? b) Esta responsabilização atinge o dano moral? c) O que são dados pessoais? c.1) O que é privacidade e o que é intimidade? c.2) Os dados pessoais são direitos fundamentais? d) A má utilização de dados pessoais é causa de dano moral?

\footnotetext{
* Doutora em Direito pela Universidad Complutense de Madrid (1993). Atualmente é professora titular da Pontifícia Universidade Católica do Rio Grande do Sul onde leciona na Graduação e no Programa de Mestrado e Doutorado em Direito. Procuradora Federal/AGU.
} 
Sem ter a pretensão de exaurir a matéria, iniciamos uma discussão acerca do tema proposto, refletindo sobre os paradigmas existentes no Direito Constitucional sobre dano moral e proteção de dados pessoais.

A utilidade do objeto deste estudo, bem como sua restrita implementação no cenário político-judiciário pátrio, faz com que, sem dúvida, esse trabalho seja apenas o ponto de partida, início de uma discussão ainda insipiente no Brasil, mas que merece destaque, dada sua evidente relevância.

\section{A RESPONSABILIDADE CIVIL DO ESTADO: UMA ABORDAGEM DA EVOLUÇÃO}

Hariou já colocava de manifesto que o Estado de Direito incorpora a necessidade de responsabilizar-se o mesmo, enquanto Administração Pública, pelos danos decorrentes de sua atividade, nas palavras do autor:

“Existem duas correções da prerrogativa da Administração ao qual reclama o instinto popular, cujo sentimento em relação ao Poder Público pode formular-se nestes dois brocardos: que atue, porém que obedeça a Lei, que atue, porém que pague o prejuízo."

Nem sempre foi assim. O princípio “the king can do not wrong”. Classicamente oriundo da idéia do Poder Imperial Romano e do Poder do Monarca calcado na concepção teocentrista, característico do período medieval, permitiu durante longos tempos, que o Estado ficasse à margem da responsabilidade pelos atos praticados por seus agentes.

O máximo alcançado, em determinado momento, foi a responsabilização direta dos agentes estatais, mas, ainda assim, essa responsabilidade era abstrata, sem atribuir aos lesados os meios aptos para tornarem efetiva a reparação.

Podemos citar como um importante avanço quanto à responsabilização do Estado, a construção jurisprudencial ou pretoriana do Conselho de Estado francês, pois este repudiava a solução dada pelo Código Civil estruturada em termos privatísticos.

O Conselho de Estado francês elaborou o regime jurídico da responsabilidade pública, informada por princípios de direito público - exorbitantes e derrogatórios do direito comum.

Esse panorama é conhecido, através das “Teorias publicístas”e nesse sentido, nas palavras de Celso Ribeiro Bastos temos que:

"É dizer, abandona-se a idéia civilista de culpa que envolve sempre negligência, imperícia e imprudência para condicioná-la à mera atuação objetiva do Estado, independentemente dos ingredientes subjetivos com que tenha atuado."

Para o autor, torna-se de menor importância o saber se o evento danoso foi praticado com culpa ou sem culpa, se era lícito ou ilícito o que importa é perquirir se houve um nexo causal entre o evento danoso e o dano de fato gerado.

${ }^{1}$ Précis de droit administratiff, Paris, 1911.

${ }^{2}$ BASTOS, Celso Ribeiro. Curso de Direito Administrativo. 6. ed. Rio de Janeiro: Saraiva, 1999 p. 211. 
É pacífico que no Estado de Direito este está controlado e se sujeita ao ordenamento jurídico, do que não resulta aceitável a criação de danos, a incidência de lesões sobre cidadãos, decorrentes do exercício de uma atividade estatal - que procura o bem estar de todos - sem o preço da sobrecarga de alguns. ${ }^{3}$

Pode-se assim sintetizar, que a atividade estatal tem o dever de não provocar danos e, se produtora de danos é responsável por sua reparação.

Em conexão com a matéria, podemos trazer à discussão o controle dos atos administrativos e neste sentido Juarez Freitas ${ }^{4}$ faz referência à "subordinação das ações estatais à dignidade da pessoa humana”. Sustenta o renomado autor que:

“A Administração Pública, por conseguinte, goza de prerrogativas, não tanto por supremacia, mas por legitimidade funcional. Nessa linha, gradativamente temos que rever antigos conceitos, porquanto faz-se indispensável reconhecer que a Administração resulta tão ou mais devedora de obediência ao principio da dignidade da pessoa humana, mormente quando se espera que seja exemplar o seu acatamento dos princípios, não apenas o da legalidade, mas do complexo inteiro dos princípios supremos. ${ }^{5,}$

Nesse contexto, é que se insere a necessidade evidente de que o Estado seja responsável patrimonialmente pelos danos que gerar. Todavia, faz-se importante salientar a presença de elementos ou, por melhor dizer, pressupostos fundamentais para que a responsabilidade seja imputada ao Estado, quais sejam: a) a ocorrência de dano, e, b) a deflagração deste a um comportamento omissivo ou comissivo, que é o que se denomina de nexo de causalidade.

Ressalta-se que o ordenamento jurídico brasileiro deu um salto no desenvolvimento da matéria ao incorporar a teoria da responsabilidade objetiva do Estado à sua Constituição, conforme o disposto no art. 37, § $6^{\circ}$.

De acordo com esta teoria, entende-se que:

(...) a responsabilização é decorrente do próprio fato, em conseqüência do risco criado, sem indagar da conduta do agente, sua negligência, imprudência ou imperícia. Deixa-se de lado o elemento subjetivo, a culpa, que é atribuída sempre a uma pessoa, o elemento risco é fundamentado no princípio da causalidade,

\footnotetext{
3 “Temos então o Estado-de-Direito como aquele em que o limite e o fundamento da ação estatal se encontra na ordem jurídica e essencialmente na base desta, a Constituição. (...) A moderna teoria das fontes, no pensamento jurídico, repousa igualmente sobre essa prevalência da lei, assim na teoria como na realidade; o próprio conceito de norma se alimenta desta concepção legalista do direito positivo. Uma série de princípios, dentro da tendência especulativa que dominou o setecentos, ocupou desde então o mundo jurídico, a começar do significativo "princípio da legalidade”, bastante ligado à justiça penal por causa inclusive da influência de Beccaria, mas em verdade presente em todos os ramos dos ordenamentos". SALDANHA, Nelson. Formação da Teoria Constitucional. Rio de Janeiro: Renovar, 2000, p. 20 e 23.

${ }^{4}$ FREITAS, Juarez. O controle dos Atos Administrativos e os Princípios Fundamentais. 2. ed. rev. ampl. São Paulo: Malheiros, 1999.

${ }^{5}$ FREITAS, Juarez. O controle dos Atos Administrativos e os Princípios Fundamentais.(...). p. 55. Ainda, por oportuno, julgamos indispensável a leitura da seguinte obra do mesmo autor: A Interpretação Sistemática do Direito. 4. ed. São Paulo: Malheiros, 2004. Nesta última obra Juarez Freitas fixa os pressupostos para uma interpretação tópico-sistemática do Direito, com base na hierarquia de valores.
} 
que é impessoal. Baseia-se a teoria do risco no equilíbrio econômico, envolvendo a idéia de justiça distributiva, como já ensinava Aristóteles. ${ }^{6}$

Passada esta primeira etapa do trabalho, que teve como fito fornecer um panorama geral sobre a responsabilidade civil do Estado, no próximo capítulo faremos uma abordagem específica a respeito do tema de fundo desta pesquisa, qual seja, a responsabilidade do Estado por Dano Moral, partindo de uma abordagem ampla até chegarmos ao Dano Moral estatal propriamente dito.

\subsection{Uma Abordagem Genérica acerca da Definição do Dano Moral}

O Dano Moral, de difícil, ou melhor, com várias definições, porém, nenhuma exata, paira sobre a modernidade causando inquietações no mundo social, sobretudo no mundo jurídico, com sua incidência nos casos concretos, aos quais cabe ao Poder Judiciário encontrar o ponto de eqüidade entre o sujeito ativo e passivo.

A doutrina, como veremos no decorrer do estudo, entende que o dano moral, embora sem uma definição fixa, é a lesão de um bem juridicamente protegido que causa uma dor imensurável na vítima - sendo que alguns agregam ainda o elemento: efeitos do dano.

Abstrai-se daí uma indagação: o que entendemos por dor, e qual a sua relação com o dano moral?

Christiano do Vale, ao estudar a matéria entendeu que: “A dor é a síndrome que arrasa o corpo e a mente do ofendido. A dor física ou moral é uma só. O dano moral, portanto, tem seu fundamento na dor no seu sentido mais extenso". ${ }^{7}$

Tal idéia é confirmada por outros doutrinadores como, por exemplo, Sílvio Rodrigues para quem: “o dano é moral quando o prejuízo experimentado pela vítima não repercute na órbita de seu patrimônio. É a mágoa, a tristeza infligida injustamente a outrem, mas que não envolve prejuízo material”. 8

Também neste mesmo sentido, Tupinambá Azevedo já se posicionou acerca da matéria entendendo que: “o dano moral é um sentimento psíquico". 9

Veja-se que a marca fundamental para esses autores é a de que a dor é o alicerce do dano moral.

No entanto, outros estudiosos entendem de forma diferente e não atribuem somente à dor o fundamento do dano moral. Assim nos chama a atenção Américo Luiz Martins ao mencionar que:

(...) a bem da verdade, alerta e corrige Eduardo Zannoni que o dano moral não é a dor, a angústia, o desgosto, a aflição espiritual, a humilhação, o complexo que sofre a vítima do evento danoso, pois esses estados de espírito constituem a

${ }^{6}$ CRETELLA JR., José. Manual de Direito Administrativo. 6. ed. Rio de Janeiro: Forense, 1992. p. 354

${ }^{7}$ VALLE, Christino Almeida do. Dano Moral: doutrina, modelos e jurisprudência. Rio de Janeiro: AIDE, 1996. p. 57.

${ }^{8}$ Apud REGO, Carlos Edson Monteiro do. Elementos de Responsabilidade Civil por Dano Moral. Rio de Janeiro: Renovar, p. 39.

9 NASCIMENTO, Tupinambá Miguel Castro do. Responsabilidade Civil do Estado. Rio De Janeiro: AIDE, 1995. p. 57. 
conseqüência do dano. O Direito não repara qualquer padecimento, dor ou aflição, mas aqueles que forem decorrentes da privação de um bem jurídico sobre o qual a vítima teria interesse reconhecido juridicamente. Os lesados indiretos e a vítima poderão reclamar a reparação em razão de dano moral, embora não peçam um preço para a dor que sentem, mas tão somente, que lhes outorguem um meio de atenuar, em parte, as conseqüências da lesão jurídica por eles sofrida. Por isso se diz que o dano moral direto consiste na lesão a um interesse que visa a satisfação de um bem extrapatrimonial contido nos direitos da personalidade (como a vida, a integridade corporal, a liberdade, a honra, a intimidade, o decoro, a imagem) ou nos atributos da pessoa (como o nome, a capacidade, o estado de família). E o dano moral indireto consiste, por sua vez, na lesão a um interesse tendente à satisfação de bens jurídicos patrimoniais, que produz depreciação a um bem extrapatrimonial (por exemplo, a perda de coisa com valor afetivo). ${ }^{10}$

Dentre as correntes doutrinárias existentes com relação à definição do dano moral, duas se destacam, a saber: a) a que se baseia na natureza do direito subjetivo violado, sustentada por Roberto Brebbia, e, b) a que se fundamenta nos efeitos da ofensa, sustentada por Artur Oscar de Oliveira Deda, José Pedro Aramendia e José de Aguiar Dias.

Destaca-se que a corrente que tem seu fundamento nos efeitos da ofensa encontra maior número de seguidores, sendo o entendimento dominante na nossa doutrina.

Assim é que segundo os representantes desta corrente, sobretudo José Antônio Remédio que ao citar afirma que para este:

“(o) caráter patrimonial ou moral do dano não deriva da natureza do direito subjetivo atingido, mas precisamente dos efeitos da lesão jurídica. E isto é tão certo, que do ataque a um bem jurídico de valor econômico pode resultar uma perda inestimável pecuniariamente. Por outro lado, da ofensa a um direto subjetivo extrapatrimonial podem resultar prejuízos materiais. Inclusive pode acontecer que, da violação de direito subjetivo, seja qual for sua índole, resultem concomitantemente prejuízos de ordem moral e danos de natureza extrapatrimonial. ${ }^{11,}$

A respeito da questão em nosso entendimento, o direito deve compensar o dano que provocou efeitos morais lesivos à vítima porque assim previstos no ordenamento jurídico.

A Responsabilidade Civil do Estado no ordenamento jurídico pátrio funda-se na Teoria do Risco Administrativo onde a obrigação de indenizar é resultante do dano materialmente causado desde que comprovado um nexo causal (art. 37, § $6^{\circ} \mathrm{CF}$ ). Esta obrigação é clara e evidente em relação ao dano material, no entanto, não tão cristalina em relação ao dano moral.

\footnotetext{
${ }^{10}$ SILVA, Américo Luís Martins da. O Dano Moral e sua Reparação Civil. 1. ed. São Paulo: Revista dos Tribunais, 1999, p. 38

11 REMÉDIO, José Antônio; SEIFARTH, José Fernando; LOZANO JR., José Júlio. Dano Moral. São Paulo: Saraiva, 2000. p. 19.
} 
José Eduardo Callegari Cenci ao citar Wilson de Melo da Silva, diz que o autor entende o dano moral:

“(...) como aquele que diz respeito às lesões sofridas pelo sujeito físico ou pessoa natural - não jurídica - em seu patrimônio de valores exclusivamente ideais, vale dizer, não - econômicos. Na conformidade desta doutrina, o dano moral, teria, como pressuposto ontológico a dor, vale dizer, o sofrimento moral ou mesmo físico inferido à vítima por atos ilícitos, em face de dadas circunstâncias (...). ${ }^{12 \text {," }}$

Também, de acordo com o mestre Celso Ribeiro Bastos, até a carta de 1988 o seu ressarcimento era quase que impossível. Ressaltamos sua afirmação:

"Mesmo quando isso se dava, era com fundamento nos danos materiais advindos do agravo moral. $\mathrm{O}$ art. $5^{\circ}, \mathrm{X}$, da vigente Constituição reza: 'São invioláveis a intimidade, a vida privada, a honra e a imagem das pessoas, assegurado o direito de indenização pelo dano material ou moral decorrente de sua violação'. ${ }^{13,}$

O preceito não restringe o dever de reparar tão-somente às pessoas privadas. Não discrimina entre umas e outras do que se infere que o Estado está também jungido a reparar o dano moral, desde que violador da intimidade, da vida privada, da honra e da imagem das pessoas.

Adotada assim, para desenvolvimento do estudo, a tese de que o dano moral se traduz como uma lesão a interesse juridicamente protegido, outra particularidade deveras importante deve ser agregada, qual seja, a sua íntima ligação com os direitos da personalidade. Tal idéia vem respaldada no entendimento de Paulo Luiz Lôbo quando o mesmo sustenta que:

"De modo mais amplo, os direitos de personalidade oferecem um conjunto de situações definidas pelo sistema jurídico, inatas às pessoas, cuja lesão faz incidir diretamente a pretensão aos danos morais, de modo objetivo e controlável, sem qualquer necessidade de recurso à existência da dor ou do prejuízo. ${ }^{14,}$

Pela idéia do autor, a responsabilidade opera-se pelo simples fato da violação (damnu in re ipsa), ou seja, se há incidência de lesão a direito de personalidade, há a necessidade de reparação do dano moral. O mestre vai além, entendendo que a responsabilidade decorrente de tal dano é baseada na teoria objetiva, ou seja, não há necessidade de prova do prejuízo, mas apenas a relação de nexo causal. Segundo o renomado autor, o dano moral:

“(...) remete à violação do dever de abstenção a direito absoluto de natureza não patrimonial. Direito absoluto significa aquele que é oponível a todos, gerando, pretensão à obrigação passiva universal. E direitos absolutos de natureza não patrimonial, no âmbito civil, para fins de danos morais, são exclusivamente os direitos da personalidade. Fora dos direitos da personalidade são apenas cogitáveis os danos materiais. ${ }^{15,}$

${ }^{12}$ CENCI, José Eduardo Callegari. Considerações sobre dano moral e a sua reparação. Revista dos Tribunais, São Paulo, nº 683, p. 45-8, set. 1992.

${ }^{13}$ BASTOS, Celso Ribeiro. Curso de Direito Administrativo. (...), p. 196.

${ }^{14}$ LÔBO, Paulo Luiz Netto. Dano Moral. Revista Jurídica, Porto Alegre, no ${ }^{\circ} 284$, p. 5-17, 2001.

${ }^{15}$ idem (...). p. 17. 
Assim referidas as correntes no próximo capítulo trataremos dos direitos da personalidade, à toda evidência protegidos por nosso ordenamento jurídico e esfera jurídica atingida diretamente pelo dano moral.

3. DOS DIREITOS DA PERSONALIDADE (OBJETO DO DANO MORAL)

Importante esclarecer que os direitos da personalidade são direitos subjetivos, isto é, cada ser humano possui e cada ser humano o exerce independente de qualquer imperativo do Estado. Além disso, tais direitos não são suscetíveis de avaliação pecuniária, eles não podem ser vendidos, trocados ou deixados de lado da esfera individual. Podemos citar como exemplos de direitos da personalidade:

a) Direito à vida: todo a pessoa que nasce com vida tem direito sobre ela, direito de permanecer com vida, todavia, não se pode dispor da vida, nem a pessoa nem o Estado, tanto é verdade que o Estado puni o homicida e proíbe a prática da pena de morte, a única exceção é prevista na Constituição Federal art. 5 , XLVII, a, em caso de guerra declarada, além de não ser permitido, do ponto de vista legal, o suicídio ou auxílio e instigação ao suicídio, justamente, porque a vida é indisponível.

b) Direito à liberdade: todos os cidadãos têm direito de ser livres, desde o nascimento até o momento de sua morte, todos podem e têm o direito de ir e vir a não ser, é claro, na hipótese do indivíduo ter cometido algum crime que enseja em seu aprisionamento.

c) Direito à integridade física e psíquica: a pessoa tem o direito de manter íntegro o seu corpo físico bem como a sua mente. A agressão, a coação física e mental é proibida, nem mesmo a pessoa pode se automutilar, ela pode dispor das partes renováveis de seu corpo como cabelo, sangue, unhas, dos órgãos duplos ou de partes de órgãos sem prejuízo de suas funções vitais. Devemos lembrar dos transplantes de órgãos post mortem, eis que eles só podem ser realizados com o devido consentimento.

d) Direito do autor: Nas palavras de Paulo Luiz Netto Lobo:

“A criação intelectual - especialmente as obras literárias, científicas e artísticas, excluído o aproveitamento industrial ou comercial - da pessoa envolve dois aspectos distintos: os direitos patrimoniais do autor, de natureza econômica e são objetos de atos jurídicos, e os direitos morais do autor', que integram os direitos da personalidade do criador, dotados de todas as características referidas: intransmissibilidade, indisponibilidade, irrenunciabilidade, imprescritibilidade, inexpropriabilidade. (...). A utilidade da obra pode ser negociada, mas nunca qualquer dos direitos morais do autor. ${ }^{16,}$

e) Direito à honra (ou reputação): tem por objeto o respeito, a boa fama, o caráter que a pessoa possui frente aos demais indivíduos. Toda pessoa goza esse direito, todavia, ele pode ter um nível maior ou menor de acordo com padrão ético e moral de cada um e, também, de acordo com o ambiente em que a pessoa vive, trabalha,

${ }^{16}$ LÔBO, Paulo Luiz Netto. Dano Moral. Revista Jurídica, Porto Alegre, nº 284, p. 5-17. 2001. Ver também RIZZARDO, Arnaldo. Direito das Coisas. Rio de Janeiro: Forense, 2003. 
estuda, etc. A honra que construímos perante o mundo social pode ser alvo de ataques dolosos ou culposos, por isso, ela é tida como um direito de personalidade muito frágil. Quando nos referimos a honra da pessoa física, a qual só ela pode sofrer desprezo, humilhação, a doutrina estabelece que estamos lidando com a honra subjetiva. Porém, a pessoa jurídica também goza de honra, é o que a doutrina chama de honra objetiva, pois ela também usufrui apreço e consideração social.

f) Direito à identidade pessoal: diz respeito ao direito, que toda pessoa, possui de ter um nome, que é tido no nosso ordenamento como absoluto e inato. O nome é composto pelo prenome, simples ou composto, que é individual, e pelo sobrenome que indica a procedência familiar. Aqui, a proteção do direito ao nome se estende a proteção do pseudônimo, que utilizado para atividades profissionais. Quando fica configurada a lesão ao nome, têm-se, conjuntamente, danos morais.

g) Direito à privacidade: aqui, nós podemos elencar uma série de direitos, tais como, o direito à imagem, à vida privada, ao sigilo e à intimidade. Tomam como nomenclatura generalizada direito à personalidade, pois, justamente não devem ser levados a público. É o que torna a vida da pessoa uma só, diferente de todas as demais vidas. Poderíamos fazer uma comparação com o material genético de cada pessoa, ninguém mais tem igual.

O direito à imagem consiste no direito de não ter seu retrato, sua figura estampada, exposta em algum lugar, público ou privado, sem a devida autorização. Quando o direito à imagem é violado, poderá estar configurado o dano material, mas sempre estará configurado o dano moral. ${ }^{17}$

O direito à vida privada está relacionado ao ambiente familiar, a casa. A Constituição Federal em seu art. $5^{\circ}$, inciso IX, estabelece que a casa é o asilo inviolável do indivíduo, ninguém pode penetrar sem o consentimento do morador, salvo em flagrante delito ou para prestar socorro ou por determinação judicial.

O direito ao sigilo está para salvaguardar as informações das correspondências e das comunicações que só dizem respeito à pessoa destinatária. Aqui, não podemos incluir como direito da personalidade o sigilo bancário, pois este revela um valor patrimonial do cliente ou do banco.

O direito à intimidade corresponde a todos os fatos, informações, acontecimentos, entre outros, que a pessoa deseja manter dentro de seu foro íntimo, somente ela tem acesso. Tudo que possa moldar a pessoa de forma singular está sob a proteção do manto do direito à intimidade. ${ }^{18}$

\section{DA RESPONSABILIDADE ESTATAL PELO DANO MORAL}

Estes são os contornos da discussão acerca de uma definição para dano moral. No entanto, para adentrarmos no mundo deste tipo de dano, com as peculiaridades e

\footnotetext{
${ }^{17}$ Entendemos que a proteção à imagem não abarca situações de exposições públicas do indivíduo eis que nestes locais não há como invocá-la. Quem se expõe em locais públicos não goza de tais prerrogativas.

${ }^{18}$ A este trabalho o Direito à Intimidade, núcleo do Direito à Privacidade, é por demais importante, pois nele se encontra a proteção de dados. Nesta senda, reservamos aos capítulos posteriores tratamento diferenciado à matéria, em especial no capítulo 5 .
} 
objetos que lhe são próprios, é imprescindível tecermos considerações acerca da responsabilidade que decorre do referido dano. Sendo assim:

“(...) se um agente viola norma de direito público que protege bem jurídico tido como relevante para o legislador, em conduta profundamente lesiva à vida social, ocorre uma reação consistente na aplicação de sanção severa, denominada pena. Esta é a responsabilidade penal (...) se o agente descumpre norma que tutela interesse meramente privado e causa um dano, poderá ser obrigado a repará-lo, por meio de pagamento de indenização ao ofendido. Nesse caso, a responsabilidade é civil. ${ }^{19,}$

A responsabilidade civil pode decorrer tanto da culpa do agente, quanto de circunstância legal que a presuma ou, ainda, de circunstância meramente objetiva. Arnaldo Marmitt ensina que:

"O instituto da responsabilidade civil se funda no dever de quem causou o dano a outrem, devido à violação de direito, de indenizar o prejuízo provocado pelo agente, ou por quem estiver sob sua responsabilidade, ou pelo fato de coisa ou animal sob sua guarda. ${ }^{20,}$

Como pressupostos da responsabilidade civil podemos elencar: a) Ação ou omissão do agente. Sempre lembrando que o agente causador do dano deve ser imputável (em se tratando de menoridade, só os menores de 16 anos são inimputáveis para a responsabilidade civil, o menor entre 16 e 18 anos é civilmente responsável). b) Dolo ou culpa. c) Dano. d) Nexo de causalidade entre o dano e a ação ou omissão.

Dentro do próprio gênero, responsabilidade civil, há uma bipartida divisão de espécies. De um lado verifica-se a responsabilidade subjetiva, onde o lesante tem de ser responsabilizado por seu ilícito, sendo que, aqui, os pressupostos são: o dano, nexo causal e a culpa. "Sobre estes três pilares apóia-se à noção fundamental da obrigação de reparar, (teoria subjetiva)" ${ }^{21}$ "É chamada de subjetiva porque depende do comportamento do agente". ${ }^{22}$

De outro, verifica-se a responsabilidade objetiva, consagradas pela teoria do risco, onde haverá o dever de reparar o dano independentemente de culpa, em casos especificados em lei, ou quando esse dano adveio de atividade, que por sua natureza, pode implicar em riscos para os direitos de outrem. Assim ensina José Antônio Remédio que "na responsabilidade objetiva, basta a existência de ação ou omissão, do nexo causal e do resultado, sendo dispicienda a indagação sobre a culpa do causador do dano". ${ }^{23}$

A responsabilidade civil sempre se baseou no conceito de culpa. Contudo, o desenvolvimento tecnológico, o aumento populacional, as novas formas de relação de empregado - empregador e, até mesmo, a relação Estado e cidadão, dentre muitos

19 REMÉDIO, José Antônio. SEIFARTH, José Fernando. LOZANO JR., José Júlio. Dano Moral. São Paulo: Saraiva, 2000, p. 2.

${ }^{20}$ MARMITT, Arnaldo. Dano moral. 1. ed. Rio de Janeiro: AIDE, 1999, p. 38.

${ }^{21}$ REGO, Carlos Edson Monteiro do. Elementos de Responsabilidade Civil por Dano Moral. p. 21.

${ }^{22}$ REMÉDIO, José Antônio. Dano Moral. (...) p. 4.

${ }^{23}$ Ibidem. 
outros fatores, tornou o conceito tradicional de culpa, em relação à responsabilidade civil, ineficaz para a proteção das vítimas, na medida em que, na maioria dos casos, quase inviável a prova da culpa do agente causador do dano. Principalmente, se no papel de agente causador do dano encontrava-se o Estado, e no da vítima, um mero cidadão. Assim, foram criados meios para amenizar essa situação, ou seja:

“a) propiciar maior facilidade à prova de culpa; b) admissão da teoria de abuso de direito como ato ilícito; c) reconhecimento de hipóteses de presunção de culpa, com reversão do ônus da prova; d) admissão da responsabilidade contratual em maior número de casos; e) adoção da teoria do risco". ${ }^{24}$

A própria Constituição de 1946, já previa a responsabilidade das pessoas jurídicas de direito público em caso de dano causado a terceiros por seus funcionários agindo nessa qualidade, cabendo ação regressiva contra o funcionário responsável, nos casos de dolo ou culpa, preceitos estes repetidos no art. 107 da Emenda Constitucional, $n^{\circ} 1$, de $1969 .{ }^{25}$ Dissecando esse princípio constitucional, chegamos à conclusão de que está, ali, implícito a teoria do risco. De acordo com essa teoria:

“(...) aquele que, no seu interesse, criar uma situação de risco será responsável quando ocorrer um dano, independente de ter agido com culpa. A obrigação de indenizar fixa-se no aspecto meramente objetivo, bastando a existência da conduta, dano e nexo causal. ${ }^{26}$ ”,

Este panorama se viu modificado na medida em que a Constituição Federal de 1988 incorporou os direitos fundamentais e as garantias para o exercício destes direitos na ânsia de reafirmar-se como um Estado Democrático de Direito. Podemos estabelecer que o Estado deverá responder de modo objetivo pelos danos materiais ou morais que, comprovados obrigando-se, assim, a reparar os prejuízos causados por seus agentes. Para Arnaldo Marmitt:

“as responsabilidades, subjetiva e objetiva, convivem harmoniosamente dinamizando-se mutuamente (...) a subjetiva é a regra, pois o lesante tem de ser responsabilizado por seu ilícito. A objetiva atende à natureza do negócio jurídico, como no transporte ou de trabalho (...) A responsabilidade objetiva funda-se na teoria do risco, onde se insere a responsabilidade decorrente de atividade perigosa, como a utilização de máquinas, veículos, objetos e outros utensílios. Haverá obrigação de reparar o dano independentemente de culpa, nos casos especificados em lei, ou, quando a atividade normalmente desenvolvida pelo agente implicar, por sua natureza, em riscos para os direitos de outrem. ${ }^{27,}$

${ }^{24}$ REMÉDIO, José Antônio. Dano Moral. (...) p. 10.

${ }^{25}$ A Constituição Federal de 1988 manteve o princípio fixado na Constituição de 1946, ao estabelecer no art. $37, \S 6^{\circ}$, que "as pessoas jurídicas de direito público e as de direito privado prestadora de serviços públicos responderão pelos danos que seus agentes, nessa qualidade, causarem a terceiros, assegurado o direito de regresso contra o responsável nos casos de dolo e culpa”. REMÉDIO, José Antônio. Dano Moral. (...). p. 32.

${ }^{26}$ Idem. p. 10

${ }^{27}$ MARMITT, Arnaldo. Dano Moral. 1. ed. Rio de Janeiro: AIDE, 1999, p. 31. 
A jurisprudência é torrencial no sentido de acolher a responsabilidade civil do Estado, de forma objetiva em relação aos danos morais provocados por seus agentes de forma direta ou por delegação.

Embora, hoje, possamos sintetizar que a ação estatal esteja adstrita ao dever de não ser produtora de danos aos particulares, traz em conseqüência o fato de que toda vez que houver dano, e constatando-se a presença remota ou próxima do Estado, dar-se-á um encargo ao Estado como finalidade do prejuízo causado. Não olvidemos, no entanto, que a presunção de culpa é relativa posto que admite excludentes.

“A presunção de culpa, oriunda da responsabilidade objetiva, constitui presunção juris tantum, presunção legal condicionada, ou presunção relativa, ou seja, aquela que, tida como verdadeira por lei, pode ser destruída pelas provas que se lhe oponham (ela existe de direito, até que se prove ao contrário).,28

O que se modifica com este panorama é que a prova necessária para exclusão de responsabilidade recai sobre o Estado e não mais sobre a vítima. Nas palavras de Arnaldo Marmitt:

“Pode a Administração liberar-se da obrigação indenizatória, mediante comprovação de que o dano foi produzido por culpa exclusiva da vítima. E sua responsabilidade poderá ser mitigada, se demonstrar que houve concorrência de culpas, dela e do lesado, na produção do resultado (do dano). Neste caso, o montante indenizatório guardara proporcionalidade com o grau de culpa de cada qual."29

Tal idéia é perfeitamente compatível com o Estado moderno que se torna cada vez mais desobrigado da prestação de serviços à sociedade delegando sua execução aos particulares.

\section{O DIREITO À INTIMIDADE COMO NÚCLEO DO DIREITO FUNDAMENTAL À PRIVACIDADE, E A PROTEÇÃO DE DANOS}

Assentados os fundamentos atinentes à matéria do Dano Moral, nas próximas linhas perquiriremos como vai tutelada a proteção de dados pessoais, sendo inevitável a conceituação da matéria e seu correto posicionamento no plano normativo, para que, ao final, tenhamos plenamente justificada a inserção da proteção de dados no núcleo duro do Direito Fundamental à Privacidade, atributo da personalidade, protegidos contra o Dano Moral. Aliás, nossos bens morais são atributos da nossa personalidade, por isso:

“(...) dizer que a honra e os outros bens morais não podem ser objeto de reparação é incidir em erro grosseiro. Pois o padecimento humano constitui lesão, ferindo a pessoa imediatamente, diretamente. Assim sendo, o dano moral é suscetível de ser compensado economicamente. ${ }^{30,}$

O Direito Fundamental à Privacidade é faceta da própria Dignidade da Pessoa

${ }^{28}$ SILVA, Américo Luiz Martins da. O Dano Moral e a sua Reparação Civil. 1. ed. São Paulo: Revista dos Tribunais, 1999, p. 18.

${ }^{29}$ MARMITT, Arnaldo. Dano Moral. 1. ed. Rio de Janeiro: AIDE, 1999, p. 33.

${ }^{30}$ VALE, Christiano de Almeida do. Dano Moral. (...) p. 22. 
Humana $^{31}{ }^{32}$, sobre valor constitucional ${ }^{33}$. Trata-se do aspecto subjetivo da Dignidade da Pessoa Humana, reconhecido inclusive na Declaração de Universal dos Direito Humanos da $\mathrm{ONU}^{34}$.

Como ponto de partida a respeito da idéia de proteção da privacidade temos o ensaio realizado pelos professores Samuel Warren e Louis Brandeis, datado de dezembro de 1890 e publicado no Volume IV da Revista de Direito da Universidade de Harvard. ${ }^{35}$

Já no final do século XIX começava a ser verificado um crescente desenvolvimento tecnológico (como, por exemplo, a fotografia instantânea) e uma nova metodologia negocial que fizeram com que fosse indispensável proteger a pessoa na dita esfera do “estar sozinho". ${ }^{36}$

\footnotetext{
${ }^{31}$ Nesta senda, Sérgio Cavalieri Filho: “(...) logo no seu primeiro artigo, inciso II, a Constituição Federal consagrou a dignidade humana como um dos fundamentos do nosso Estado Democrático de Direito. Temos hoje o que pode ser chamado de direito subjetivo constitucional à dignidade. Ao assim fazer, a Constituição deu ao dano moral uma nova feição a maior dimensão, porque a dignidade humana nada mais é do que a base de todos os valores morais, a essência de todos os direitos personalíssimos. O Direito à honra, à imagem, ao nome, à intimidade, à privacidade ou a qualquer outro direito da personalidade - todos estão englobados no direito à dignidade, verdadeiro fundamento e essência de cada preceito constitucional relativo aos direitos da pessoa humana. Programa de Responsabilidade Civil. 4. ed. São Paulo: Malheiros, 2003, p. 95.

32 "Para além das conexões já referidas (especialmente no concernente à liberdade e seus desdobramentos) - situa-se o reconhecimento e proteção da identidade pessoal (no sentido de autonomia e integridade psíquica e intelectual), concretizando-se - entre outras dimensões - no respeito à privacidade, intimidade, honra, imagem, assim como direito ao nome, todas dimensões umbilicalmente vinculadas à dignidade da pessoa, tudo a revelar a já indiciada conexão da dignidade, não apenas com um direito geral ao livre desenvolvimento da personalidade, mas também com os direitos de personalidade em geral”. SARLET, Ingo Wolfgang. Dignidade da Pessoa Humana e Direitos Fundamentais na Constituição Federal de 1988. 3. ed. Porto Alegre: Livraria do Advogado, 2004, p. 86.

${ }^{33}$ Ver capítulos 1.9 e 2.3. Ainda, como ensina Ingo Sarlet, citando Paulo Bonavides: "Com efeito, embora aqui não se vá desenvolver mais este ponto, nunca é demais lembrar - até mesmo para firmarmos nossa posição pessoal - que a condição de princípio é integralmente compatível com o reconhecimento da plenitude eficacial e, portanto, da plena vinculatividade da dignidade da pessoa humana na sua dimensão jurídico-normativa, seja na perspectiva objetiva, seja como fundamento de posições subjetivas. Neste sentido, não haveria como deixar de colacionar a luminosa (embora não de todo incontroversa) exortação de Paulo Bonavides, que, referindo-se justamente ao princípio da dignidade da pessoa humana, afirmou que "sua densidade jurídica no sistema constitucional há de ser portanto máxima e se houver reconhecidamente um princípio no trono da hierarquia das normas, esse princípio não deve ser outro senão aquele em que todos os ângulos éticos da personalidade se acham consubstanciados”. SARLET, Ingo Wolfgang. Dignidade da Pessoa Humana e Direitos Fundamentais na Constituição Federal de 1988. 3. ed. Porto Alegre: Livraria do Advogado, 2004, p. 75.

${ }^{34}$ Sobre o tema, ver capítulo 1.9 .

${ }^{35}$ BRANDEIS, Louis D. e WARREN, Samuel D. The Right to Privacy. Retirado do site: www.lawrence.edu/ fast/boardmaw/Privacy_brand_warr2.html, acesso em: 30 de abril de 2007.

${ }^{36}$ Nas palavras de Warren e Brandeis: "Recent inventions and business methods call attention to the next step which must be taken for the protection of the person, and for securing to the individual what Judge Cooley calls the right 'to bel et alone'. Instantaneous photographs and newspaper enterprise have invaded the sacred precincts of privare and domestic life; and numerous mechanical devices threaten to make good the prediction that "what is whispered in the closet shall be proclaimed from the house-tops". BRANDEIS, Louis D. e WARREN, Samuel D. The Right to Privacy. (...) p. 02. Ainda, "A doutrina sempre lembra que o Juiz americano Cooly, em 1873, identificou a privacidade como o direito de ser deixado tranqüilo, em paz, de estar só: Right to be alone”. SILVA, José Afonso. Curso de Direito Constitucional, 20. ed. São Paulo: Malheiros Editores, 2001, p. 205.
} 


\section{Segundo Maria Cláudia Cachapuz:}

"Há uma garantia de respeito à privacidade do cidadão, por uma proteção outorgada ao seu direito de pensar, sentir e emocionar-se. Reconhece-se, para tanto, não um direito de propriedade - e esta é a relevância doutrinária do escrito ao ressaltar o entendimento que passava a ser acolhido pelos tribunais anglo-saxões -, senão o de efetivo resguardo à inviolabilidade da personalidade do indivíduo. Por isso a possibilidade, ainda no século XIX, de que cartas pessoais, sem conteúdo literário ou de publicação, pudessem ter sua divulgação não autorizada tutelada por um direito de privacidade, tratando-se de violação a um direito de personalidade do indivíduo. Mesma hipótese se verifica em relação à publicação de manuscritos sem a autorização de seu autor, ainda que inicialmente associada a tutela à mesma proteção exigida a direitos de crédito.”37

Na Constituição Federal brasileira de 1988, art. 5º, inc. X, o Direito à Privacidade foi colocado dentre os direitos fundamentais ${ }^{38}$. Segundo Alexandre de Moraes a "proteção constitucional consagrada no inciso $\mathrm{X}$ do art. $5^{\circ}$ refere-se tanto a pessoas físicas quanto a pessoas jurídicas”. ${ }^{39}$ A respeito do foco da tutela constitucional sobre a vida privada assevera José Afonso da Silva:

“A tutela constitucional visa proteger as pessoas de dois atentados particulares: (a) ao segredo da vida privada; e (b) à liberdade da vida privada. O segredo da vida privada é condição de expansão da personalidade. Para tanto, é indispensável que a pessoa tenha ampla liberdade de realizar sua vida privada, sem perturbação de terceiros. São duas variedades principais de atentados ao segredo da vida privada, nota Kayser: a divulgação, ou seja, o fato de levar ao conhecimento do público, ou a pelo menos de um número indeterminado de pessoas, os eventos relevantes da vida pessoal e familiar; a investigação, isto é, a pesquisa de acontecimentos referentes à vida pessoal e familiar; envolve-se aí também a proteção contra a conservação de documento relativo à pessoa, quando tenha sido obtido por meio ilícitos. O autor ressalta o fato hoje notório de que o segredo da vida privada é cada vez mais ameaçado por investigações e divulgações ilegítimas por aparelhos registradores de imagens, sons e dados, infinitamente sensíveis aos olhos e ouvidos."40

\footnotetext{
${ }^{37}$ CACHAPUZ, Maria Cláudia. Intimidade e Vida Privada no Novo Código Civil Brasileiro: Uma leitura orientada no Discurso Jurídico. Porto Alegre: Sergio Antonio Fabris Ed., 2006, p. 79.

38 “Art. $5^{\circ}$ Todos são iguais perante a lei, sem distinção de qualquer natureza, garantindo-se aos brasileiros e aos estrangeiros residentes no País a inviolabilidade do direito à vida, à liberdade, à igualdade, à segurança e à propriedade, nos termos seguintes: (...) X - são invioláveis a intimidade, a vida privada, a honra e a imagem das pessoas, assegurado o direito a indenização pelo dano material ou moral decorrente de sua violação”. BRASIL. Constituição da República Federativa do Brasil. 37. ed., São Paulo: Saraiva, 2005, p. 05-6.

${ }^{39}$ MORAES, Alexandre. Direito Constitucional. 18. ed. São Paulo: Atlas, 2005, p. 47. "À exceção do direito à honra, tutelado no âmbito penal e pela lei de imprensa, não havia uma proteção expressa desses direitos no nosso ordenamento jurídico antes do atual Texto Constitucional, o que não impedia, v.g., que o direito à imagem já fosse reconhecido nos Tribunais”. FARIAS, Edilsom Pereira de. Colisão de Direitos: A honra, a intimidade, a vida privada e a imagem versus a liberdade de expressão e informação. Porto Alegre: Sérgio Antonio Fabris Edito, 1996, p. 104.

${ }^{40}$ SILVA, José Afonso. Curso de Direito Constitucional, 20. ed. São Paulo: Malheiros Editores, 2001, p. 207-8.
} 
Está tramitando um Projeto de Lei do Senado Federal, de $n^{\circ} 321 / 2004$ com relação à matéria. Tal projeto, foi apresentado em 10 de novembro de 2004 e atualmente está na Comissão de Constituição e Justiça aguardando relator. ${ }^{41}$

Levando-se em consideração que no Brasil os Direitos Fundamentais são autoaplicáveis inclusive na relação entre particulares, o simples fato de que ainda não existe uma lei específica que trate da Proteção de Dados Pessoais não é por si só bastante à defesa da inexistência de tutela. ${ }^{42}$

O Direito Fundamental à vida privada teve seu conteúdo delimitado pelo Tribunal Europeu de Direitos Humanos (TEDH) com três distintos âmbitos de proteção, a saber: (a) direito de defesa da esfera privada; (b) direito de autodeterminação corporal; (c) direito de livre escolha do estilo de vida. ${ }^{43}$

Assim, o direito à vida privada e o direito à intimidade não se confundem ${ }^{44}$, sendo o segundo espécie de núcleo do primeiro e, assim, merecendo maior atenção e substancial restrição em termos de relativização. ${ }^{45}$

A proteção de dados pessoais, pelo menos daqueles dados que merecem maior segregação, insere-se no âmbito da intimidade - mas com essa não se confunde estando assim em posição nuclear no que tange ao direito fundamental à privacidade. Neste sentido leciona Luis Ángel Ballesteros Moffa:

\footnotetext{
${ }^{41}$ Segundo informações retirados do site: www.senado.gov.br, acesso em 2 de junho de 2007.

${ }^{42}$ O Prof. Ingo Sarlet, sem esquecer da importância das normas ditas programáticas, identifica e pontua com muita proficiência a problemática da eficácia imediata dos direitos fundamentais lembrando que o art. $5^{\circ}$, $\S 1^{\circ}$, da Constituição Federal de 1988 faz tal opção justo pela possibilidade de esvaziamento da capacidade de instituir o novo de certos direitos fundamentais, no mínimo pela demora legislativa, que acabariam por se tonar letra morta da Constituição, assevera o autor: "Com base no exposto, e partindo da premissa de que não há como tomar a sério os direitos fundamentais se não se levar a sério o disposto no art. $5^{\circ}, \S 1^{\circ}$, de nossa Constituição, constata-se, desde logo, a necessidade de não subestimarmos (nem superestimarmos) o significado e alcance desta norma. Que este preceito se aplica tão-somente aos direitos fundamentais (sem exceção), e não a todas as normas constitucionais, como aparentemente quer fazer crer parte da nossa doutrina, constitui, por si só, conclusão que assume uma relevância não meramente secundária. SARLET, Ingo Wolfgang. A Eficácia dos Direitos Fundamentais. Porto Alegre: Livraria do Advogado, 1998 p. 243.

${ }^{43}$ Ver RAMIRO, Mónica Arenas. El derecho Fundamental a la Protección de Datos Personales en Europa. Valência: Tirant, 2006, p. 66-70. Nesse estudo, a autora espanhola posiciona o desenvolvimento legal, doutrinário e jurisprudencial do tema da proteção de dados pessoais, dando ênfase, em um primeiro momento, para a diferenciação da vida privada e da intimidade, fixando os pressuposto distintivos da matéria - que por nós será abordada com maior percuciência no capítulo 3.1.

${ }^{44}$ Sobre o tema ver: SAMPAIO, José Adércio Leite. Direito à Intimidade e à Vida Privada: uma visão jurídica da sexualidade, da família, da comunicação e informações pessoais, da vida e da morte. Belo Horizonte: Del Rey, 1998.

${ }^{45}$ Sobre o tratamento dado à matéria vejamos o posicionamento do Tribunal Europeu de Direitos Humanos (TEDH): "Para garantizar el 'derecho al respeto a la vida privada y familiar', el TEDH ha ido delimitando ese ámbito de 'esfera privada' cuyo respeto el Convenio se compromete a garantizar, y a pesar de que el ámbito de la esfera privada haya sido configurado por el TEDH y extensamente analizado por la doctrina, como ocurre también en relación con otros derechos, no se trata de un ámbito perfecta y definitivamente delimitado. El âmbito que el TEDH define como 'esfera privada' se protege en los Estados firmantes mediante el reconocimiento de los correspondientes derechos fundamentales (derecho a la intimidad, derecho a la dignidad...) que no siempre coinciden exactamente con el derecho a la vida privada y familiar reconocido en el CEDH (Convênio Europeu de Direitos Humanos)”. RAMIRO, Mónica Arenas. El derecho Fundamental a la Protección de Datos Personales en Europa. Valência: Tirant, 2006, p. 55.
} 
"En un esfuerzo por sintetizar y a la vez ordenar los importantes asuntos que encierra la vertiente constitucional del derecho en estudio, puede afirmarse que son dos, en líneas generales, los problemas jurídicos planteados, aunque intrínsecamente conectados. En primer lugar, si la protección de datos personales constituye tan sólo un derecho de exclusiva configuración legal, o por el contrario, un derecho fundamental, com las trascendentes consecuencias que de ello se derivan. $\mathrm{Y}$ en segundo lugar, y partiendo ya del presupuesto de que efectivamente este instituto presenta un sustrato constitucional, cuál es la específica vía o fórmula desde la que el mismo encuentra dicho acómodo constitucional, esto es, si es a través del reconocimiento de un derecho autónomo en la materia o por su incardinación en otros clásicos derechos fundamentales, particularmente en la intimidad."46

A definição mais simples e precisa a respeito do que vem a ser dados pessoais é de autoria do TEDH (Tribunal Europeu dos Direitos Humanos), e versa o que segue: "Dados pessoas são qualquer informação relativa a um indivíduo identificado ou identificável”. Mais o mesmo TEDH diz que o conteúdo e o limite dos direitos a proteção de dados pessoais devem ser vistos conforme o tipo de dado e a sua utilização. ${ }^{47}$

\section{CONCLUSÕES}

Como se pode verificar, muitos são os caminhos a serem trilhados na busca da resolução do problema aqui discutido. O fato é que o Estado Moderno já deu um grande passo ao admitir que se possa imputar a este ente o dever de reparar os prejuízos causados. Tal concepção incorporada ao nosso ordenamento jurídico reafirma o próprio fundamento que em última instância dota este mesmo Estado da prerrogativa de exercer o poder impondo a ordem, mas por outro lado, impinge-lhe o dever de arcar com o ônus do exercício deste poder sempre e quando a ordem jurídica for afrontada. Avanço maior representa a adoção de teorias publicistas baseadas no risco administrativo invertendo o ônus da prova e imputando ao mais "forte" o dever de provar sua isenção.

Ademais, note-se que no campo do dano moral relacionado com a responsabilidade civil do Estado se faz necessária uma previsão legal própria, que incorpore os paradigmas da Constituição (direitos da personalidade), bem como de outros textos legais e que, além disso, traga uma definição jurídica objetiva e quais as hipóteses de incidência de tal dano. Isto porque a matéria se refere à proteção de interesse privado frente ao interesse público.

Com tal idéia o que se pretende é retirar o subjetivismo que paira sobre o dano moral afastando as incertezas que dificultam aos operadores do Direito o fazer a justiça com eqüidade, principalmente no que tange à proteção de dados pessoais núcleo do Direito à Privacidade.

${ }^{46}$ MOFFA, Luis Ángel Ballesteros. La Privacidad Electrónica: Internet en el Centro de Protección. Valência: Tirant, 2005, p. 82.

47 "El TEDH ha especificado, además, que los datos protegidos por el derecho que estamos analizando no son únicamente los que hacen referencia a la vida privada, sino también cualquier outro dato sobre la vida pública de una persona siempre que afecte al desarrollo de su personalidad, porque, como es evidente, no todos los datos personales, es decir, 'todas las informaciones relativas a um individuo identificado o identificable' son igual de relevantes desde el punto de vista de la protección de la vida privada”. RAMIRO, Mónica Arenas. El derecho Fundamental a la Protección de Datos Personales en Europa. Valência: Tirant, 2006, p. 80. 